анализировать свои наблюдения, сопоставлять факты, обобщать, выявлять причинноследственные связи. Задача педагога научить детей работать с картой и извлекать из нее максимум полезных знаний. Но помимо работы с традиционной картой и глобусом современному педагогу нужно заинтересовать обучающихся, с помощью различных приложений и сервисов, направленных на изучение географии онлайн.

$$
* * *
$$

1. Берлянт А.М. Картография: Учебник для вузов. / А.М. Берлянт - М.: Аспект Пресс, 2002. - 336 с.

2. Сухоруков В.Д. Методика обучения географии: учебник и практикум для вузов / В.Д. Сухоруков, В.Г. Суслов. - 2-е изд., перераб. И доп. - Москва: Юрайт, 2020. - 365 с.

3. Лаппо Г. М. География и Гоголь / Г. М. Лаппо // География / М.: Первое сентября, 2009. - вып. 9. c. $10-14$

4. Скуратович О.Я. Работа с картографическими материалами на уроках географии в общеобразовательных школах / О.Я. Скуратович К.: НПП «Картография», 2000.

\title{
Симакина Н.И.
}

Тренажёр отработки этапов проектного менеджмента программного обеспечения как средство геймификации в курсе «Практическое экстремальное программирование»

Пермский государственный гуманитарно-педагогический университет (Россия, Пермь)

doi: $10.18411 / \mathrm{lj}-12-2020-161$

idsp: ljournal-12-2020-161

\section{Аннотация}

Геймификация (игрофикация) - это использование игровой атрибутики и игровых элементов для повышения вовлеченности в неигровой деятельности. Концепция широко используется в области маркетинга, продаж, управления персоналом, а теперь все чаще и в сфере образования. Целью данной статьи является разработка интерактивной среды как средства для практических решений игрового образовательного процесса. Полученные результаты свидетельствуют о высоком уровне принятия геймификационных программ среди студентов, а также о необходимости развития данной формы обучения.

Ключевые слова: геймификация, игрофикация, формы обучения студентов, игровые механики, интерактивная среда, мотивация на обучение, вовлеченность, дистанционное обучение, электронное обучение, веб-разработка, формирование компетенций, проектный менеджмент, гибкие методологии, Agile, Kanban, информационная система, проектирование информационных систем, экстремальное программирование, правила и практики экстремального программирования.

\section{Abstract}

Gamification - gamification) is the use of game attributes and game elements to increase engagement in non-game activities. The concept is widely used in the field of marketing, sales, personnel management, and now more often in the field of education. The purpose of this article is to develop an interactive environment as a means for practical solutions to the game educational process. The results indicate a high level of acceptance of gamification programs among students, as well as the need to develop this form of education.

Keywords: gamification, gamification, forms of student learning, game mechanics, interactive environment, motivation for learning, engagement, distance learning, e-learning, web development, competence building, project management, flexible methodologies, Agile, Kanban, information system, information system design, extreme programming, rules and practices of extreme programming. 
В сегодняшних реалиях развития цифровой экономики Российской Федерации обучение требует наличие инструментов формирования компетенций не только в формате встреч в учебном заведении, но и на расстоянии. Дистанционные инструменты обучения становятся на передний план $[1,2,4]$, и наша задача не просто сделать такие инструменты, а создать качественный, эффективный и функциональный продукт. В качестве такого инструмента в курсе «Практическое экстремальное программирование» стала интерактивная среда: разработанный тренажёр отработки этапов проектного менеджмента разработки программного обеспечения. Это информационная платформа для автоматизации проектного менеджмента и работы команды в единой информационной среде с поддержкой современной гибкой методологии разработки Agile. В качестве интегрированной среды разработки (IDE) была выбрана Microsoft Visual Studio Code. В качестве базы данных была выбрана СУБД MySQL. Разработка информационной системы происходила в операционной системе Windows 10 и на веб-сервере, предоставленным хостингом. Разработка включала в себя работу с инструментами синтаксиса: HTML, CSS, PHP, JavaScript.

Изучение курса «Практическое экстремальное программирование» [3] происходит в виде игры живого действия. Вся группа разбивается на команды по 6-8 человек. Каждый участник регистрируется в системе, указывая свои навыки и желаемую роль в команде. С учетом этих данных создается рабочая группа. Каждая рабочая группа производит разработку программного обеспечения по выбранной тематике.

Управление проектом было реализовано в виде меню проекта, меню организации групп пользователей, меню планирования, меню управления нормативносправочной информацией и общего чата. Для управления задачами и прикреплёнными решениями была реализована интерактивная Kanban доска позволяет быстро реагировать на новые изменения проекта и одновременно с этим создавать живой поток задач для разработчиков (рис.1).

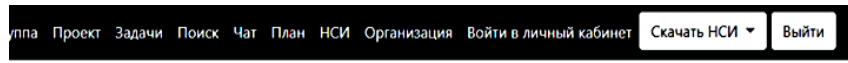

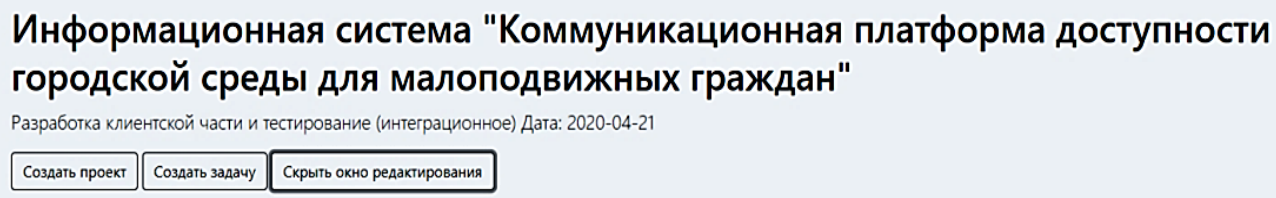

Бэклог

Задача номер: 31

тип: Тестирование

Приоритет: Средний

Трудоёмкость: 30

Исполнитель:
Описание: Тестирование (внутренне

компонентное и внутреннее интеграционное)

Деалайн: 2020-04-07

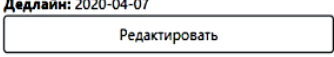

Задача номер: 32

Tип: Разработка

Приоритет: Средний

ТрУАоёмкость: 50
Исполнитель:

Описание: Разработка клиентского приложения

Деалайн: 2020-04-07

Редактировать

Задача номер: 33
Разработка

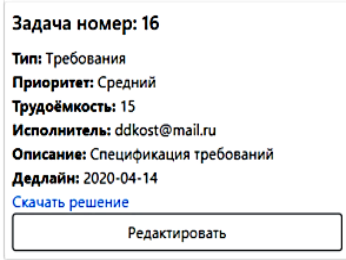

Редактироват
Тестирование

Задача номер: 29

Tип: Разработка

Приоритет: Средни

Tрудоёмкость: 50

Исполнитель: devZhulanov.A.A@gmail.com Описание: Разработка серверной части

приложения

Дедлайн: 2020-04-14

Скачать решение

Редактировать

Рисунок 1. Kanban доска

\section{]} (n)

(n)

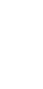

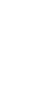


планирования итераций и релизов. Кроме того к каждой задаче можно редактировать комментарий, в который проектный менеджер, участники проекта, преподаватель или ментор может писать соответствующую информацию. Это могут быть оценки решений, вопросы, фиксирование внутренних этапов задачи или просто комментарий. В целом она помогает реализовать практически все практики экстремального программирования. Функционал системы также позволяет моментально построить диаграммы текущего состояния и отслеживать работы каждого участника проекта.

Система позволяет сформировать диаграмму Гантта по задачам проекта (рис.2), чтобы отследить этапы проекта.

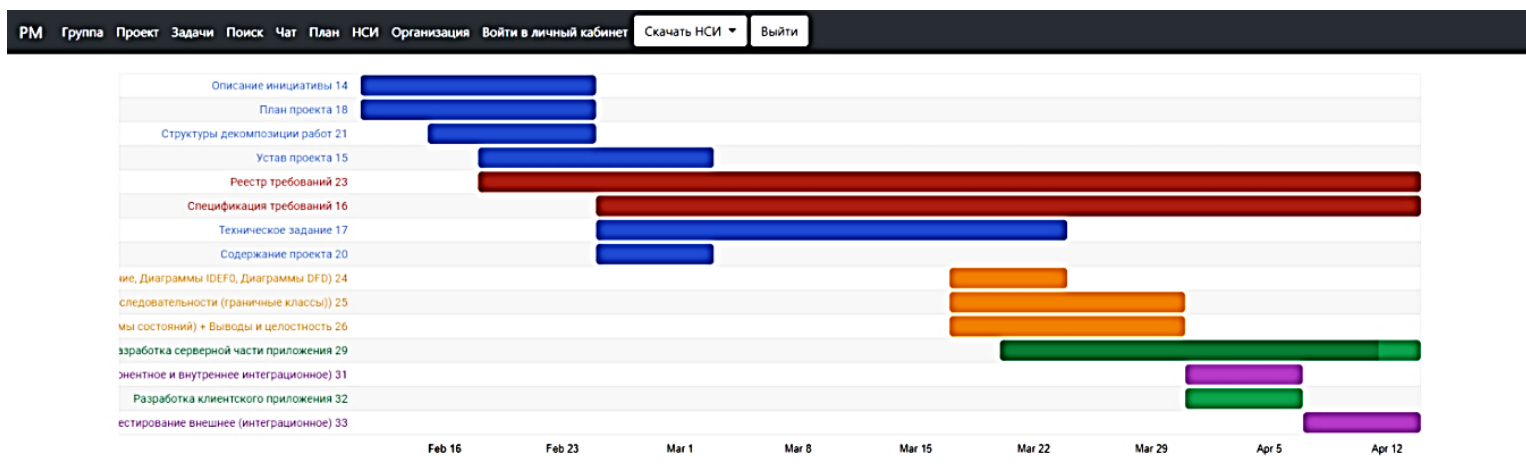

Рисунок 2. Диаграмма Гантта по задачам проекта

Разными цветами отмечены разные типы задач: требования, проектирование, разработка, тестирование или документация. Сама диаграмма интерактивная и, если навести мышь, будет показана более детальная информация по задаче.

Кроме того система позволяет формировать статистику по проекту в реальном времени, что позволяет более качественно следить за процессом разработки.

При этом для работы в общем пространстве не нужно находиться в едином классе или офисе, так как вся информация от участников стекает в единую веб-среду. Благодаря адаптивному интерфейсу, проектному менеджеру или преподавателю для принятия эффективных управленческих решений не нужен даже стационарный компьютер. Все действия можно производить с мобильных устройств, подключенных к интернету.

Руководитель проекта или преподаватель смогут контролировать план для каждого проекта в отдельности, трудозатраты в часах по задачам, а также состояние проекта в целом и процент выполнения каждой задачи, представленной на диаграмме Гантта с заданными временными промежутками. А команда своевременно реагировать на новые задачи, визуализированные на Kanban board, и работать с ними, в том числе и прикреплять решения.

Применение игровой механики в курсе «Практическое экстремальное программирование имеет несколько назначений $[5,6]$ : погружение в новую деятельность через игровую модель; изменение отношения к деятельности через игровую модель; возможность посмотреть на деятельность новым взглядом. Также отработка навыков в игровой среде - реиграбельность оправдывает повторение. Реализация данной автоматизированной информационной системы и внедрение её в процесс обучения, позволит сформировать у обучающихся навыки проектного менеджмента и работы в команде, с условием дистанционной работы в общем пространстве. Данная информация будет полезна не только преподавателю, но и назначенному проектному менеджеру проекта, для принятия своевременных управленческих решений.

$$
* * *
$$

1. Усть-Качкинцева Е.Ю., Симакина Н.И. Инновационные педагогические технологии в преподавании дисциплины «Проектирование информационных систем» // Сборник научных 
трудов по итогам международной научно-практической конференции «Педагогика и психология: научные приоритеты учёных», № 1. -Пермь, 2016. - С. 47-50.

2. Рыжков С.А., Симакина Н.И. Создание банка инновационных приемов и форм дистанционного обучения школьной информатики // Материалы всероссийской научно-методической конференции по вопросам применения ИКТ в образовании «Информатика в школе: прошлое, настоящее и будущее». Федеральное государственное бюджетное образовательное учреждение высшего профессионального образования «Пермский государственный национальный исследовательский университет», Национальный исследовательский университет, Высшая школа экономики, Пермское отделение Академии информатизации образования РФ, ООО Учебный центр «Информатика».- Пермь, 2014.-С. 200-202.

3. Атеев К.О., Симакина Н.И. Применение информационной среды для проведения занятий в курсе "Практическое экстремальное программирование"// Рецензируемый научный журнал «Тенденции развития науки и образования». Июнь 2020 г. №62, Часть 12. - Изд. НИЦ «Л-Журнал», 2020. -c.1418 [Электронный ресурс] - URL: http://ljournal.ru/wp-content/uploads/2020/06/lj06_2020_p12.pdf

4. Симакина Н.И. «Практическое экстремальное программирование». [Электронный ресурс] - URL: https://moodle.pspu.ru/course/view.php?id=2463

5. Комиссаров А. Игровое образование. [Электронный ресурс] - URL: https://www.facebook.com/groups/mosaicum/

6. Войтенко А.И. Геймификация или работа в форме игры/А.И. Войтенко, А. Голубева//Новое поколение. - 2014. - №7. - С.32-34

\section{Тебиева А.Б., Тимошкина Н.В. \\ Роль музейной педагогики в современной школе \\ ФГБОУ ВО «Северо-Осетинский государственный университет имени Коста Левановича Хетагурова (Россия, Владикавказ)}

doi: $10.18411 / \mathrm{l}-12-2020-162$

idsp: ljournal-12-2020-162

\section{Аннотация}

В статье подчеркивается, что эффективность образовательно-воспитательного воздействия музея во многом зависит от того, насколько школьники подготовлены к восприятию информации. Порождая разнообразные эмоции у школьников, музеи одновременно создают основу для воспитательного воздействия. Ведь познание через эмоции - самый эффективный путь в воспитании убеждений, моральных ценностей и норм, эстетических идеалов.

Ключевые слова: музейная педагогика, учебный процесс, учащиеся

\section{Abstract}

The article emphasizes that the effectiveness of the educational impact of the Museum largely depends on how well students are prepared for the perception of information. By generating a variety of emotions among schoolchildren, museums simultaneously create the basis for educational impact. After all, knowledge through emotions is the most effective way to educate beliefs, moral values and norms, and aesthetic ideals.

Keywords: museum pedagogy, educational process, students

Что всплывает у нас перед глазами, когда мы вспоминаем свои школьные экскурсии? Наверное, здание музея со старинными колоннами, пыльные деревянные витрины с различными экспонатами, строгие смотрители и скучные экскурсии... Так ли это?

Актуальность этой проблемы очевидна, однако ее разрешение тормозится отставанием научного осмысления культурно-педагогических процессов, протекающих в музейной среде, слабостью технического оснащения информационнокоммуникативной деятельности музеев, недостаточным владением рядом сотрудников современными технологиями психолого-педагогического воздействия на разные 